\title{
ICING ON ELECTRIC RAILWAYS
}

\author{
By D. H. Coombs, B.Sc., A.M.I.C.E., A.M.I.Mech.E., A.M.I.Loco.E. \\ (London Transport Executive)
}

THE major icing problem affecting electric railways of the London Transport Executive is the interference with the collection of current caused by ice formations on top-contact current rails. Before discussing this subject there are other icing difficulties which deserve mention. Ice on the slide chairs or in the actuating, locking or detecting movements of rail points can prevent proper movement resulting in failure, and it has long been a matter of particular maintenance attention in bad weather to secure the freedom from ice of switches by such means as greasing of metal parts, mechanical cleaning and the application of common salt or de-icing fluids. On the London Transport system this hazard has been met by the installation of electrically operated oil-heater-pipe circuits through the slide chairs of switches. Electric resistance heaters have also been tried. In the United States gas and kerosene burning heaters are used, but do not appear to have found favour in this country. Icing has on occasion also interfered with the operation of signals and has brought down telephone lines, but these are aspects which do not appear to have caused serious interference on the London Transport system, partly no doubt because of the design of the signal and telephone installations.

Mechanical appliances fitted to rolling stock for the removal of icy accretions on current rails have generally been found to be inadequate, so also have thermal devices fitted to the rails, such as electric heaters. Therefore various de-icing compounds have been applied to the rail. These compounds have to meet in varying degrees the following requirements:

(a) Must have a small change of viscosity with change of temperature.

(b) Must have a good "wetting" characteristic in spreading evenly without running off the area treated.

(c) Must not seriously affect electrical contact between shoe and rail.

(d) Conversely must not sensibly reduce the insulation of either the current rails or of the running rails, which requirement calls for a low conductivity.

(e) Must be non-corrosive, which seems to preclude the use of electrolytes, and must be innocuous to paint, rubber, varnish and other materials likely to be exposed to the compound.

( $f$ ) Must not adhere to the rail in a cumulative way, nor carbonize in situ.

(g) Must be sufficiently persistent to achieve its purpose and must not "dry out" too quickly, but be susceptible to being dispersed by weathering to avoid undesirable local concentrations of a conductive or ballast-fouling medium.

(h) Must not separate out on storage for say two years.

(i) Must be reasonable in cost.

(j) Must be water-soluble and a good freezing point depressant, thus retarding ice formation; or water-insoluble, water-displacing and water-repellant, thus reducing ice adhesion.

The choice of a particular compound for a particular section of railway is naturally affected by a number of factors which vary as between different railway systems. The frequency of service is a fundamental factor. The design of track installations, including signalling track circuits, and of the rolling stock are also of importance, both in respect to the compound used and its method of application.

Methods of application have been either mobile, by drip feed or pressure spray from either normal service or special vehicles, or static, by a wet roller or felt wick or pressure spray, on to 
collector shoes from fixed installations on the track. In general the circumstances of London Transport have favoured fixed track installations called de-icing units, whereby the shoes of every train pass over rollers wetted with a de-icing fluid which is in this way spread along the conductor rail. On the other hand the different requirements of Regions of the Railway Executive have been met by the installation of equipment to spray de-icing liquids either from service trains or from special purpose "sleet locomotives."

Compounds used for rail de-icing are either water-soluble freezing point depressants, or waterrepellent adhesion reducers, or a combination of both. In the first group proprietory and domestic mixtures which have been used have been variously compounded of glucose, dextrin, sodium chloride, reducing sugars, sodium nitrate, glycerol, ethylene glycol and sodium acetate, with additions for thickening, thinning or spreading as necessary. The second group comprises waterrepellent adhesion reducers such as special mineral oils. A third group of dual purpose de-icing liquids consist mainly of glycol, and mineral oils, wool grease and glucose.

The extent to which the de-icing provisions described now provide a complete answer to icing interference with top contact third and fourth rail electric traction systems is not certainly established. Every several years a glazed frost of severity occurs when perhaps rain falls on freezing ground, or a thaw is checked, or ice is formed by local condensation on to current rails below freezing point. A thin film of de-icing fluid a few thousandths of an inch thick can dispel hoar frost but clearly cannot dispel an ice coating of more than say $\frac{1}{8}$ in. $(3.2 \mathrm{~mm}$.) thickness. Its value in reducing the adhesion of such an ice coating must be the subject of more experience in the field before the value of existing de-icing techniques in the freak conditions which characteristically occur only once in several years can be predicted with certainty.

In using de-icing precautions London Transport and Regions of the Railway Executive are guided by a weather forecasting service specially provided for them by the Meteorological Office. The form of the bulletin supplied and a scale of icing risk utilized have been the subject of joint discussion between the railway staff and the meteorologists. Arising from these talks, and in order to augment available data by which weather quantities may be correlated to icing conditions embarrassing to electric railways, an arrangement has been concluded between London Transport and the Meteorological Office whereby hydrographs and thermometers fitted with remote recording gear have been installed at Barons Court, in West London. Humidity, air temperature and rail temperature are automatically and continuously recorded and observers are posted as necessary to note the nature and adhesion of icing deposits formed on a test section of rail.

The installation was completed too late in the winter of $1949-50$ to yield conclusive data, but as a pilot meteorological post it has proved quite satisfactory. It is hoped that in due course the information supplied by this and other similar posts will enable the forecasters to work on the basis of both local and general data affecting the icing risk to electric railways which are not now available.

\title{
ICING IN COLD STORES
}

\author{
By G. G. Lilley, B.A.(Mech. Sc.), A.M.Inst.R. \\ (Armstrong Cork Company)
}

IT is proposed here to examine three sets of conditions in the cold storage industry where ice formation is harmful, together with possible solutions.

I. Ice formation on the inside surfaces of cold rooms and more especially on airlock walls

Let us consider a typical layout consisting of two sub-zero cold stores at say $-15^{\circ} \mathrm{F}$. $\left(-26^{\circ} \mathrm{C}\right.$. $)$ separated by a smaller airlock, the walls between the stores and the airlock being typically of 